\title{
RESEARCH ON PEKING UNIVERSITY SUPERCONDUCTING ACCELERATOR FACILITY (PKU-SCAF)*
}

\author{
K. Zhao ${ }^{\dagger}$, S. W. Quan, X. Y. Lu, J. K. Hao, B. C Zhang, Y. L. Hu, \\ L. F. Wang, R. Xiang, F. Zhu, J. J. Zhuang\#", J. E. Chen \\ Institute of Heavy Ion Physics, Peking University, Beijing 100871, P. R. China \\ \# Guest professor of Peking University
}

\section{Abstract}

Peking University Superconducting Accelerator Facility (PKU-SCAF) is under development now. This facility is mainly composed of a DC-SC photocathode injector and a main accelerator with 9-cell cavity. It will provide high quality electron beams with $1 \mathrm{~mA}$ average current and 20 $\mathrm{MeV}$ energy.

\section{INTRODUCTION}

The purpose of PKU-SCAF is to provide high quality electron beams with high average current. The facility is mainly composed of a DC-SC photocathode injector[1][2] and a superconducting accelerator with 9-cell cavity[3]. It will be operated at continuous wave mode. Since superconducting technology is used, the whole facility will be a compact one. As to the 9-cell cavity, we hope to use TESLA technology. Thus, It should be collaboration between TESLA and PKU.
PKU-SCAF will supply a lot of research opportunity to related research fields at Peking University. For example, through the design and construction of PKU-SCAF, we hope to learn and grasp the most advanced superconducting technology; through the research of high average power FELs, we hope to provide a user facility for various scientific or industrial applications; Using the laser and the electron bunches provided by PKU-SCAF, we can do some theoretical researches and principle-proof experiments of the interaction between the high power laser and the ultrashort electron bunch.

\section{PKU-SCAF}

Figure 1 shows the layout of Peking University Superconducting Accelerator Facility (PKU-SCAF). It consists of the DC-SC photocathode injector[2], the superconducting accelerator, the RF-power system, and the laser driver system.

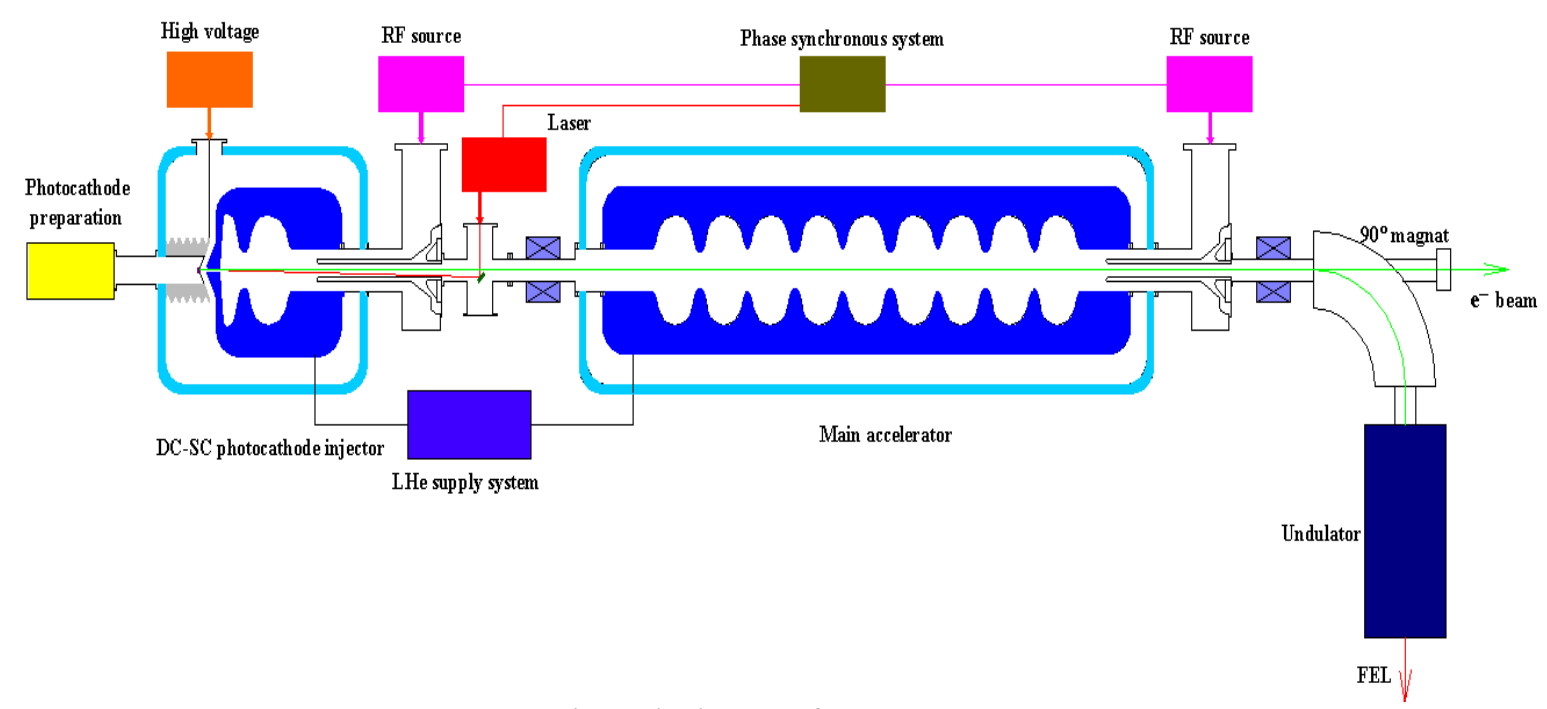

Fig.1 The layout of PKU-SCAF

The DC-SC photocathode injector (Fig. 2) combines a pierce gun with a $1+1 / 2$ cell superconducting cavity. This design has several advantages. First, it can avoid the decrease of $\mathrm{Q}$ value so that SC cavity can be operated at very high gradient; secondly, the separation of the

\footnotetext{
*Supported by NSFC(19735004)

†Email:zhao@pku.edu.cn
}

photocathode from SC cavity can avoid the consistent problem between them. Since the distance between the photocathode and the SC cavity is very short, the emittance growth is not serious. Thus, this kind of injector can provide high quality electron beams with high average-current for the main accelerator. 


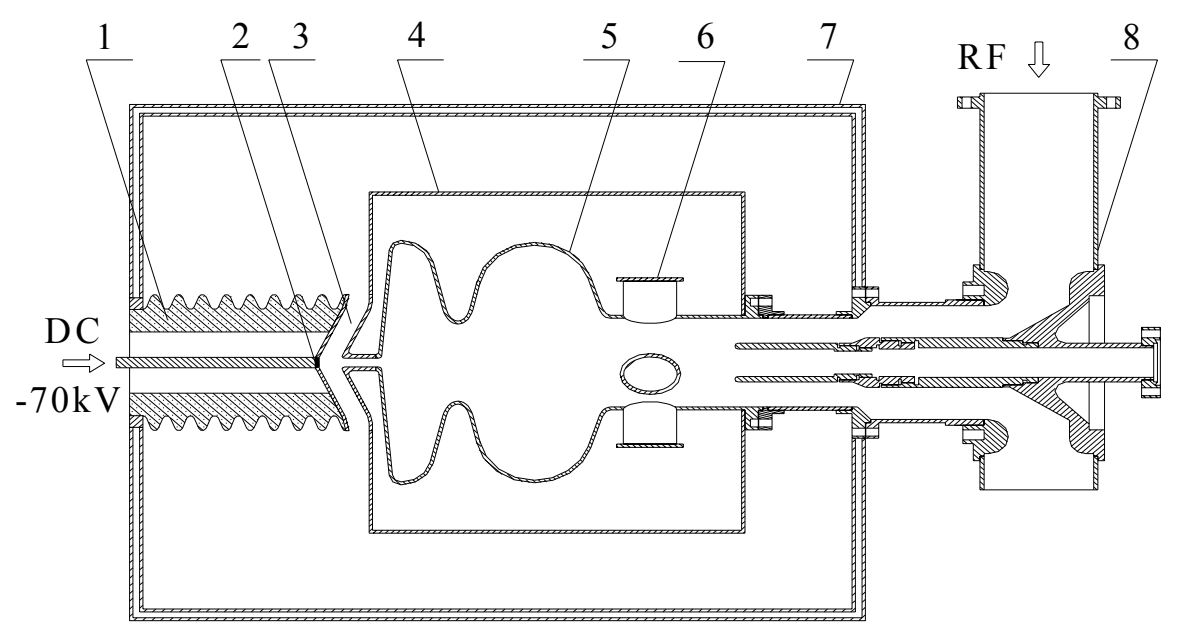

Fig. 2 Configuration of DC-SC photocathode injector

(1) Ceramics insulation (2) Photocathode (3) Pierce gun (4) LHe tank

(5) SC cavity (6) HOM coupler (7) LN shield (8) Coaxial input coupler

As to the main accelerator, we will use the 9-cell capture cavity [4] of the TESLA. It should be able to work at continuous wave mode. The energy of the electron bunches got from the main accelerator is about 20-25 $\mathrm{MeV}$ and the current of the electron beam is about $1 \mathrm{~mA}$.

The RF system consists of two RF sources, one is a 1.3 $\mathrm{GHz}, 5 \mathrm{~kW}$, CW solid-state power source for the DC-SC injector, another is a $1.3 \mathrm{GHz}, 20 \mathrm{KW}, \mathrm{CW}$-mode power source for the 9-cell cavity.

The drive laser is used to deliver IR light pulses $(800 \mathrm{~nm})$ to the cathode. In order to obtain high average current, the repetition rate of the laser pulses should be several tens $\mathrm{MHz}$. The laser system is mainly composed of a CW frequency-doubled diode-pumped Nd:YAG laser which provides energy to pump a $\mathrm{CW}$ mode-locked
Ti:sapphire oscillator. A synchronous system is designed to control the phases of the two RF sources and the laser system.

\section{SIMULATION OF BEAM DYNAMICS}

\subsection{The beam parameters after The DC-SC photocathode injector}

The process of simulating the performance of the injector has been completed. Now the injector is under construction. The initial conditions and the simulation results are shown in table 1 . The results show that the injector can meet our requirements.

Table 1 Simulation results of the DC-RF injector

\begin{tabular}{|c|c|c|c|c|}
\hline \multirow{3}{*}{ Electron bunch } & Initial conditions & \multicolumn{2}{c|}{ Simulation results } \\
\cline { 2 - 5 } & Radius & $3.0 \mathrm{~mm}$ & Anode inclination & $65^{\circ}$ \\
\cline { 2 - 5 } & Length & $10 \mathrm{ps}$ & Synchronous phase & $-50^{\circ}$ \\
\cline { 2 - 5 } & Charge & $60 \mathrm{pC}$ & Energy & $2.43 \mathrm{MeV}$ \\
\cline { 2 - 5 } SC cavity & Emittance & $0 \mathrm{~mm}-\mathrm{rad}$ & Radius & $2.8 \mathrm{~mm}$ \\
\hline \multirow{3}{*}{ Pierce gun } & Average gradient & $15 \mathrm{MV} / \mathrm{m}$ & $\Delta \mathrm{E}_{\mathrm{k}} / \mathrm{E}_{\mathrm{k}}(\mathrm{rms})$ & $2.63 \%$ \\
\cline { 2 - 5 } & $\begin{array}{c}\text { Distance between } \\
\text { cathode and anode }\end{array}$ & $15 \mathrm{~mm}$ & Bunch Length & $7.8 \mathrm{ps}$ \\
\cline { 2 - 5 } & Cathode voltage & $-70 \mathrm{kV}$ & $\varepsilon_{\mathrm{x}}(90 \%, \mathrm{n})$ & $8.249 \mathrm{~mm}-\mathrm{mrad}$ \\
\cline { 2 - 5 } & Anode voltage & $0 \mathrm{kV}$ & $\varepsilon_{\mathrm{y}}(90 \%, \mathrm{n})$ & $8.832 \mathrm{~mm}-\mathrm{mrad}$ \\
\cline { 2 - 5 } & & & $\begin{array}{c}5.223 \mathrm{keV}- \\
\text { degrees }\end{array}$ \\
\hline
\end{tabular}

\subsection{The beam parameters after the 9-cell cavity}

The electron beam from the DC-SC injector will be injected into the 9-cell capture cavity. PARMELA[5] is used to obtain the beam properties at the output of the capture cavity. Figure 3 is the electric field distribution in the 9-cell cavity. The simulation results under different accelerating gradients are listed in table 2. From the table, we can come to a conclusion that combination of DC-SC photocathode injector with the 9-cell main accelerator can provide high quality electron beams. 


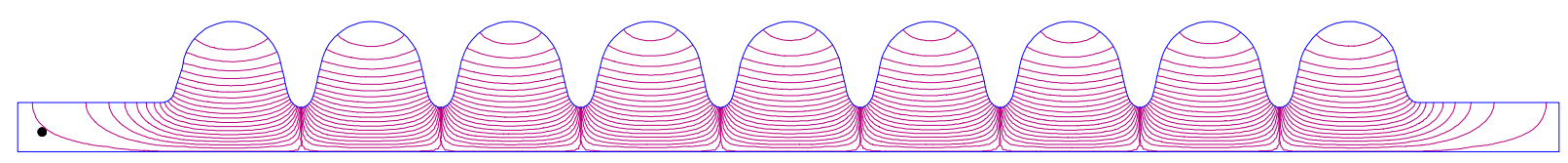

Fig.3 Electric field distribution in the 9-cell cavity

Table 2 Simulation results of PKU-SCAF

\begin{tabular}{cccccc}
\hline $\mathrm{E}_{\text {acc }}(\mathrm{MV} / \mathrm{m})$ & Phase & $\begin{array}{c}\varepsilon_{\mathrm{x}}(90 \%, \mathrm{n}) \\
(\mathrm{cm}-\mathrm{mrad})\end{array}$ & $\begin{array}{c}\varepsilon_{\mathrm{y}}(90 \%, \mathrm{n}) \\
(\mathrm{cm}-\mathrm{mrad})\end{array}$ & $\Delta \mathrm{E}_{\mathrm{k}} / \mathrm{E}_{\mathrm{k}}(\%)$ & $\mathrm{E}_{\mathrm{k}}(\mathrm{MeV})$ \\
\hline 25 & 20 & 0.8799 & 0.8116 & 0.24 & 24.91175 \\
\hline 20 & 20 & 0.7936 & 0.7408 & 0.29 & 20.40224 \\
\hline 15 & 20 & 0.7138 & 0.6693 & 0.40 & 15.55215 \\
\hline 10 & 20 & 0.6625 & 0.6275 & 0.53 & 11.38277 \\
\hline
\end{tabular}

\section{CONCLUSION}

A superconducting facility will be constructed by the RF superconducting group at Peking University. It can supply high quality beams with high average current, normalized emittance lower than $3 \pi \mathrm{mm}$-mrad, and energy about $20 \mathrm{MeV}$. It mainly contains a DC-SC photocathode injector and a 9-cell superconducting cavity. The beam dynamics analysis has been completed. The injector will be completed at the end of 2001, and the manufacture of the 9-cell cavity is on our schedule.

\section{ACKNOWLEDGEMENTS}

We want to thank our guest professor Dr. D. Proch for his continuous support. Prof. Zhang Shiwen also gives us much help on the construction of the drive laser system.

\section{REFERENCES}

[1] K. Zhao, R.L. Geng, L.F. Wang et al. Nucl. Instr. \& Meth. in Phys. Res., 1996, A375:147-149

[2] K. Zhao, J.K. Hao, Y.L.Hu, et al. Research on DC-RF photocathode injector for high average power FEL. To be published in Nucl. Instru. \& Meth. in Phys., 2001.

[3] D. Proch, Superconducting cavities for accelerators, Rep. Prog. Phys. 61 (1998) 431-482.

[4] Conceptual Design of a $500 \mathrm{GeV}$ e+e- Linear Collider with Integrated X-ray Laser Facility, DESY, Vol1: 298-320, 1997

[5] James H Billen. PARMELA Documentation. LANL, 1997. 